\title{
QUÍMICA NA PRÁTICA: DIVULGANDO A QUÍMICA NAS ESCOLAS
}

\author{
Regina Maria Queiroz De Mello ${ }^{1}$ \\ Liliana Micaroni ${ }^{2}$ \\ Mariana Marques Da Cunha ${ }^{3}$
}

\begin{abstract}
Resumo: Sabe-se que as atividades experimentais permitem uma melhor visualização na prática do que os alunos aprendem nas aulas teóricas, o que os possibilita uma maior compreensão dos conteúdos de Química. No entanto, muitas escolas públicas não apresentam condições de ofertar atividades experimentais devido à carência de material, escassez de tempo ou dificuldade por parte dos professores para preparar as aulas. O projeto visa minimizar essa falta de atividades experimentais nas escolas de ensino públicas através do uso de experimentos demonstrativos de Química. Tais experimentos são selecionados e confeccionados por estudantes voluntários de graduação da UFPR, de diferentes cursos (Química, engenharia Química e farmácia) sob orientação das professoras coordenadoras do projeto. Através do agendamento de visitas, são apresentados para estudantes e professores do ensino médio dessas escolas 5 kits de experimentos num sistema de rodízio. Os estudantes voluntários da UFPR explicam e instigam a curiosidade dos estudantes da escola sobre o tema de cada kit. Até o momento, foram atendidos 609 estudantes de 3 escolas públicas. O projeto contribuiu para divulgação da Química entre os estudantes do ensino médio despertando um maior interesse por essa disciplina e contribuiu para o processo de formação acadêmica e cidadã dos estudantes de graduação envolvidos no projeto.
\end{abstract}

Palavras chave: Experimentos de Química; escolas públicas; extensão; ensino médio.

\section{CHEMISTRY IN PRACTICE: DISSEMINATING CHEMISTRY IN SCHOOLS}

Abstract: It is known that experimental activities allow a better visualization in the practice of what students learn in theoretical classes, which allows them a greater understanding of the contents of chemistry. However, many public schools are not able to offer experimental activities due to lack of material, lack of time or difficulty on the teachers' part to prepare the classes. The project aims to minimize this lack of experimental activities in public schools through the use of demonstrative chemistry experiments. These experiments are selected and made by undergraduate UFPR students from different courses (chemistry, chemical engineering and pharmacy) under the guidance of the coordinating teachers of the project. Through scheduled visits, 5 kits of experiments are presented to students and high school teachers of these schools in a rotating system. The UFPR volunteer students explain and instill the curiosity of the school's students on the theme of each kit. To date, 609 students from 3 public schools have been attended. The project contributed to the dissemination of chemistry among high school students, inspired a greater interest in this discipline and contributed to the process of academic and citizenship training of undergraduate students involved in the project.

Keywords: Chemical experiments; public schools; extension; high school.

\footnotetext{
${ }^{1}$ Universidade Federal do Paraná.

${ }^{2}$ Universidade Federal do Paraná.

${ }^{3}$ Universidade Federal do Paraná.
} 


\section{Introdução}

O ensino de diversos conteúdos de Química é de difícil compreensão ao estudante e, muitas vezes, esses conteúdos são passados aos estudantes do ensino médio apenas na teoria, sem atividades práticas. A existência de limitações no Ensino de Química praticado na Educação Básica é observada desde a década de 70. Entre os problemas relacionados estão a carência de experimentação e de interação com o cotidiano, a descontextualização, a linearidade, a fragmentação dos conteúdos, a desconsideração da História da Química, o uso frequente de fórmulas, equações e símbolos, os quais muitas vezes nada representam ao aluno (ZANON; MALDANER, 2007). A realização de atividades práticas é de fundamental importância no processo de ensino aprendizagem, fazendo com que o aluno aprenda, compreenda e fortaleça o conhecimento adquirido (POLETTI, 2001). Isso ocorre porque os estudantes visualizam na prática o que aprenderam na teoria. Dessa forma, a Química deixa o campo do abstrato e passa para o campo do concreto.

O desinteresse dos estudantes pela Química tem sido associado à falta de relação entre a Química ensinada na escola e o cotidiano dos estudantes e à falta de atividades experimentais que possam relacionar a teoria com a prática. A dificuldade dos estudantes em compreender conteúdos de Química pode ser minimizada através da utilização de aulas experimentais, que os auxiliam na compreensão dos temas abordados e em suas aplicações no cotidiano, já que proporcionam uma relação entre a teoria e a prática (ARROIO, 2006). Desse modo, o ensino não fica restrito a uma abordagem apenas formal possibilitando associar a Química com os avanços tecnológicos que afetam diretamente a sociedade (CHASSOT, 1993).

É consenso que a experimentação desperta interesse entre os estudantes, independentemente do nível de escolarização (GIORDAN, 1999). As atividades experimentais são capazes de proporcionar um melhor conhecimento ao estudante e há diversos trabalhos com reflexões que visam abranger a importância da atividade experimental no ensino de Química (GIORDAN, 1999), (ARROIO, 2006) e (AMARAL, 1996).

Gaspar e Monteiro (2005) apresentaram algumas ideias da teoria sociocultural de Vygotsky, que acreditam oferecer indicações válidas para a melhoria do processo de ensino e aprendizagem com o uso das atividades experimentais de demonstração em sala de aula. Usando o referencial da teoria de Vygotsky (1989), as aulas práticas estimulam a curiosidade, a iniciativa e a autoconfiança, aprimoram o desenvolvimento de habilidades linguísticas, Revista Extensão em Foco, nº 17, Out./ Dez. (2018), p. 149 -163. 
mentais e de concentração e exercitam interações sociais e trabalho em equipe. Do ponto de vista do professor, essas atividades permitem identificar erros de aprendizagem e atitudes e dificuldades dos alunos.

No entanto, muitas escolas públicas não apresentam condições de ofertar atividades experimentais devido a diversas dificuldades como falta de material, ausência de um laboratório de Química e até mesmo falta de tempo e dificuldade por parte dos professores para o preparo as aulas laboratoriais. Muitos professores não sabem administrar uma aula prática por não ter segurança no conteúdo que está transmitindo, porque não aprendeu a conduzir esse tipo de atividade na Universidade, ou pela falta de incentivo por parte da escola que impõe algumas barreiras, e até mesmo, o excesso de matérias para passar em um curto período de tempo (CUNHA, 1995).

Uma maneira de minimizar essa falta de atividades experimentais na escola é incentivar seus estudantes a participarem de atividades de interesse disponibilizadas por instituições de ensino superior, como os projetos de extensão, que apresentem experimentos demonstrativos.

Os experimentos demonstrativos ajudam a focar a atenção do estudante nos comportamentos e propriedades de substâncias e auxiliam, também, a aumentar o conhecimento e o interesse do estudante pela Química. O processo de aprendizagem é facilitado quando são relacionados os conceitos teóricos com a experimentação, mesmo que seja através de experimentos demonstrativos (GIORDAN, 1999) e (ARROIO, 2006).

De acordo com a resolução 72/11 da Universidade Federal do Paraná (UFPR), a Extensão Universitária é um processo educativo, cultural e científico que viabiliza a relação transformadora entre a UFPR e os demais segmentos da sociedade (RESOLUÇÃO No72/11CEPE). Sendo essa atuação transformadora voltada prioritariamente à formação acadêmica e a necessidades sociais, os objetivos do projeto de extensão "Química na Prática" são ofertar experimentos demonstrativos de Química para a comunidade escolar visando minimizar a falta de atividades experimentais nas escolas públicas, divulgar e despertar a curiosidade e o interesse dos estudantes do ensino médio das escolas públicas pela Química, contribuindo na formação acadêmica e cidadã dos estudantes de graduação envolvidos no projeto.

\section{Metodologia}

Revista Extensão em Foco, nº 17, Out./ Dez. (2018), p. 149 -163. 
Estudantes voluntários de graduação da UFPR participantes do projeto, sob orientação das professoras coordenadoras do projeto, realizaram a seleção e montagem de 12 experimentos de Química, no Laboratório de Química Geral do Departamento de Química-UFPR. Os experimentos montados são: (i)-Densidade e Separação de misturas, (ii)-Estrutura atômica: Teste de chama e Luminescência, (iii)- Soluções aquosas: condutividade elétrica, ácidos e bases de Arrhenius e escala de pH, (iv)- Dispersões e Propriedades Coligativas, (v)- Evidências de reações Químicas, (vi)-Reações de oxirredução, (vii)- Células eletroquímicas galvânicas e eletrolíticas, (viii)- Cinética Química, (ix)- Equilíbrio Químico, (x)- Equilíbrio em Fase Aquosa (Análise Volumétrica), (xi)- Funções Orgânicas e (xii)- Polímeros Sintéticos.

O Projeto “Química na Prática”, fez parceria e visitou três escolas públicas na cidade de Curitiba para a apresentação dos experimentos: Escola Estadual Prof. Máximo Atílio Asinelli (6 a 8 de julho de 2016), Colégio Estadual Professor Lysímaco Ferreira da Costa (7 a 10 de abril de 2017) e Colégio Estadual Santa Rosa (27 e 28 de junho de 2017).

O primeiro passo da visita consiste na ida das coordenadoras do projeto até a escola para conhecer o espaço de laboratório e verificar se há alguma vidraria, se existem pias e o tipo das tomadas elétricas para que seja providenciada a vidraria faltante e as extensões elétricas. Nesse momento houve também um contato informal com a equipe pedagógica, a diretoria da escola e o(s) professor(es) de Química.

A metodologia de apresentação consistiu em selecionar em conjunto com o professor ou professora de Química da escola, 5 dentre os 12 kits de experimentos montados durante o $1^{\circ}$ ano do projeto. Após esta etapa, foi agendada a visita e neste dia, os estudantes voluntários de graduação da UFPR, de diferentes cursos de graduação (Química, engenharia Química e farmácia), junto com as professoras coordenadores do projeto, foram até a escola. Os estudantes de graduação apresentaram os experimentos aos estudantes do ensino médio, que foram divididos em 5 grupos. Cada grupo permaneceu em torno de 10 minutos em cada experimento, referente a um kit de experimento de Química. Após esse tempo, eles trocaram de bancada num sistema de rodízio, de modo a permitir a interação com todos os experimentos. Os estudantes voluntários da UFPR explicaram e instigaram a curiosidade dos estudantes da escola sobre o tema de cada kit. A Figura 1 ilustra como o laboratório da escola pública foi organizado pela equipe do projeto para receber os estudantes do ensino médio. A próxima etapa foi a aplicação de um questionário, cujo preenchimento é facultativo. As perguntas constantes nesse questionário podiam ser respondidas com sim, não ou talvez e foram as seguintes: (1) Você Revista Extensão em Foco, nº 17, Out./ Dez. (2018), p. 149 -163. 
ficou satisfeito com o Projeto? (2) Você participaria novamente do Projeto, com a apresentação de outros experimentos? (3) Os experimentos contribuíram para um melhor entendimento da disciplina de Química? (4) Você aprendeu com os experimentos? (5) Você entendeu a explicação dada para os experimentos? (6) Você gostou dos experimentos apresentados?

(a)

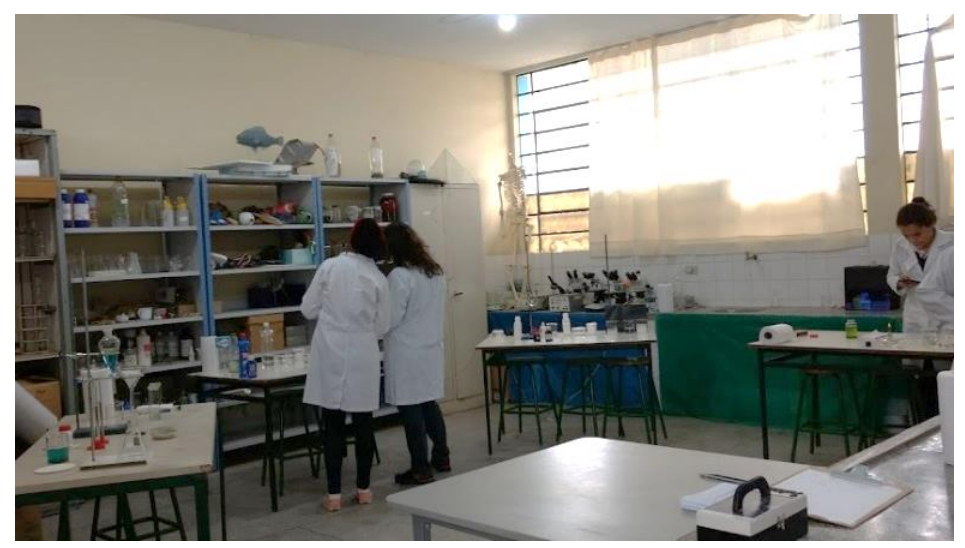

(b)

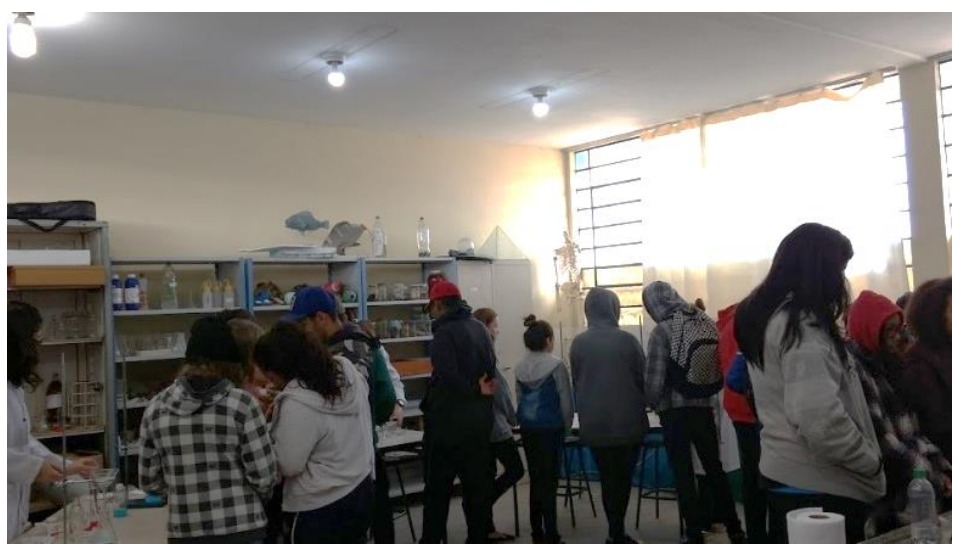

Figura 1 - Vista geral da visita ao Colégio Estadual Santa Rosa. (a) antes e (b) depois da entrada dos estudantes do ensino médio no laboratório da escola. Fonte: arquivos do projeto "Química na Prática” (PROEC 114/2016).

\section{Resultados e discussão}

O Projeto "Química na Prática" atua desde maio de 2016, quando foi iniciado o preparo dos experimentos de Química de baixo custo e ao mesmo tempo atrativos aos estudantes do ensino médio. Os experimentos são testados e montados por estudantes voluntários de graduação da UFPR, de diferentes cursos de graduação (Química, engenharia Química e farmácia), junto com as professoras coordenadoras do projeto.

Até o momento, num período de aproximadamente 18 meses, o Projeto foi implementado em três escolas estaduais, sendo sempre bem recebido tanto pela equipe Revista Extensão em Foco, nº 17, Out./ Dez. (2018), p. 149 -163. 
pedagógica, quanto pela diretoria da escola e pelos professores de Química, que demostraram grande interesse na atividade de extensão.

Os experimentos tiveram explicação teórica simples, induzindo os estudantes a relacionarem teoria e prática envolvidas em cada experimento. Nesta etapa, houve transferência de conhecimento, bem como incentivo aos estudantes para tirarem dúvidas e curiosidades, num ambiente informal.

A primeira escola a qual o "Química na Prática" foi o apresentado foi o Colégio Estadual Prof. Máximo Atílio Asinelli, no período entre 6 e 8 de julho de 2016, vide Figura 2. Nessa escola, foram atendidos 136 alunos do primeiro, segundo e terceiro anos do ensino médio. Para os estudantes do primeiro ano os experimentos foram: (i) destilação e separação de misturas (ii) estrutura atômica: teste da chama e luminescência (iii) soluções aquosas: condutividade elétrica, ácidos e bases de Arrhenius e escala de $\mathrm{pH}$ (iv) dispersões e propriedades coligativas. Para os estudantes do segundo e terceiro ano os experimentos foram: (i) soluções aquosas: condutividade elétrica, ácidos e bases de Arrhenius e escala de pH (ii) evidências de reações Químicas (iii) reações de oxirredução (iv) células eletroquímicas galvânicas e eletrolíticas. A próxima etapa constituiu na aplicação de um questionário aos alunos, cujo preenchimento não foi obrigatório.

(a)

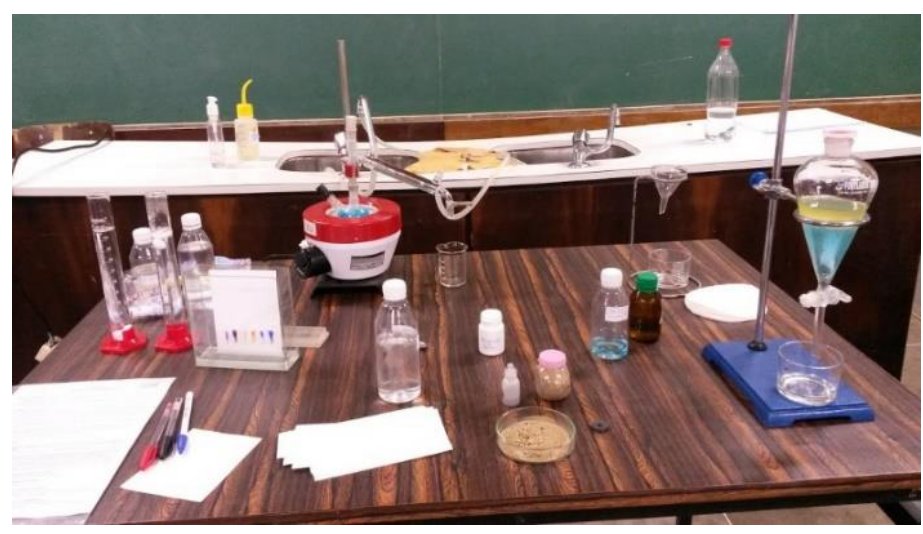

Revista Extensão em Foco, nº 17, Out./ Dez. (2018), p. 149 -163. 
(b)

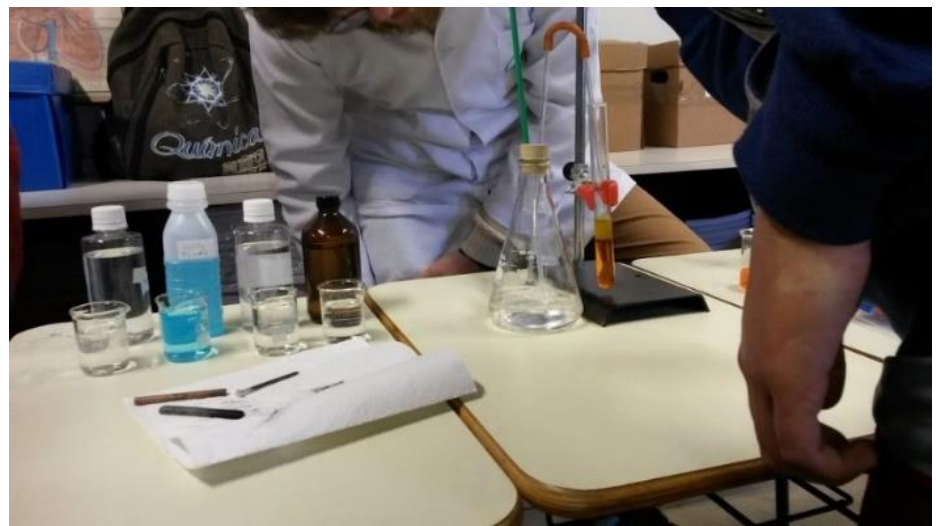

Figura 2- Experimentos apresentados no Colégio Estadual Prof. Máximo Atílio Asinelli. (a) Densidade e Separação de Misturas; (b) Reações de oxirredução (em detalhe: simulando um bafômetro). Fonte: arquivos do projeto "Química na Prática" (PROEC 114/2016).

No início do ano de 2017, foram levados os experimentos para alunos do primeiro e do terceiro ano do ensino médio do Colégio Estadual Prof. Lysímaco Ferreira da Costa, nos dias 7 e 10 de abril, vide Figura 3. Foram atendidos 261 estudantes e os experimentos apresentados foram: (i) destilação e separação de misturas (ii) estrutura atômica: teste da chama e luminescência (iii) soluções aquosas: condutividade elétrica, ácidos e bases de Arrhenius e escala de $\mathrm{pH}$ (iv) células eletroquímicas galvânicas e eletrolíticas (v) polímeros sintéticos.

(a)

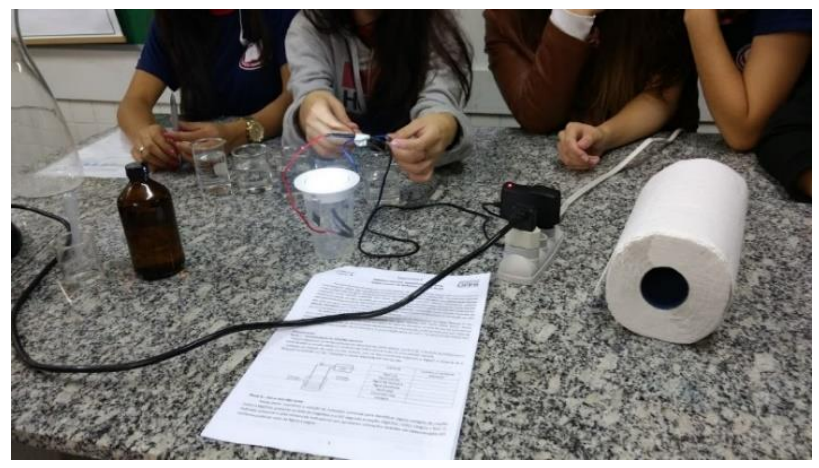

Revista Extensão em Foco, nº 17, Out./ Dez. (2018), p. 149 -163. 
(b)

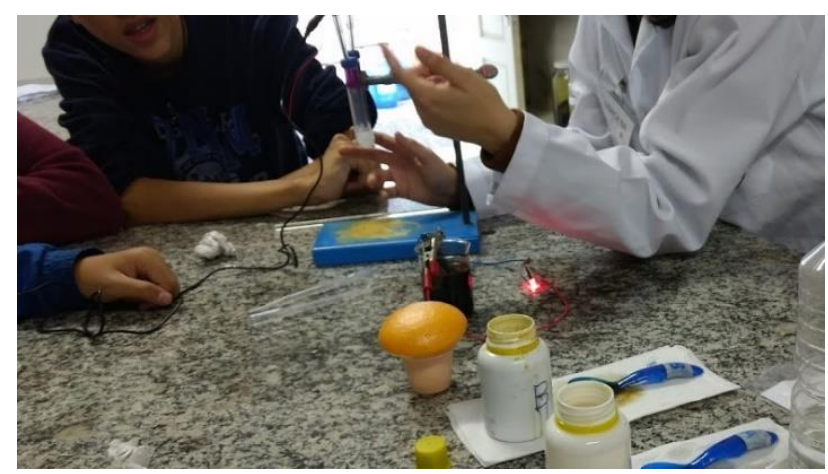

Figura 3- Experimentos apresentados no Colégio Estadual Prof. Lysímaco Ferreira da Costa. (a) Condutividade elétrica; (b) Pilha, eletrólise e polímero sintético. Fonte: arquivos do projeto "Química na Prática" (PROEC 114/2016).

Nos dias 27 e 28 de junho de 2017, foram apresentados os experimentos no Colégio Estadual Santa Rosa, Figura 4. Foram atendidos 212 estudantes do primeiro e segundo ano do ensino médio e os experimentos foram: (i) destilação e separação de misturas (ii) estrutura atômica: teste da chama e luminescência (iii) soluções aquosas: condutividade elétrica, ácidos e bases de Arrhenius e escala de pH (iv) células eletroquímicas galvânicas e eletrolíticas (v) equilíbrio químico.

(a)

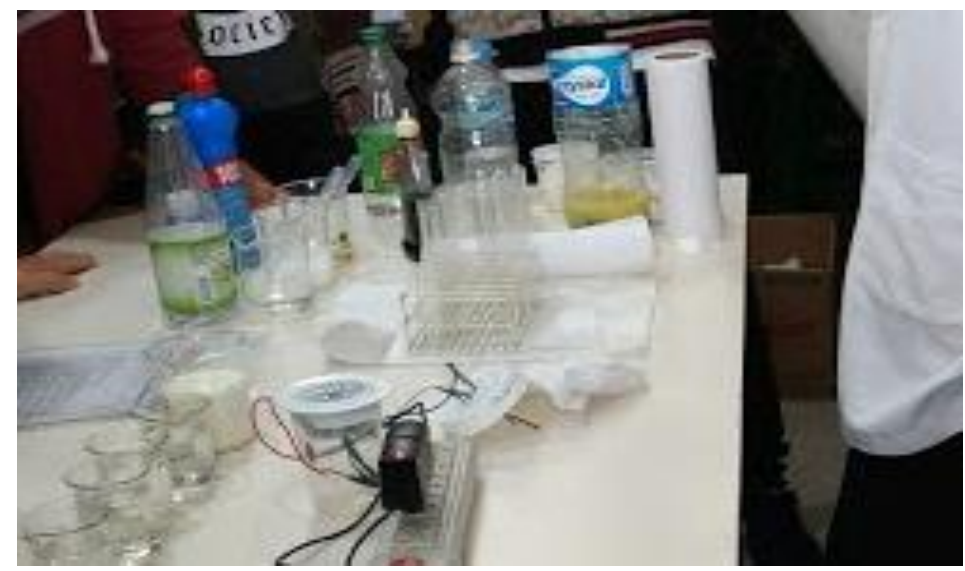

Revista Extensão em Foco, nº 17, Out./ Dez. (2018), p. 149 -163. 
(b)

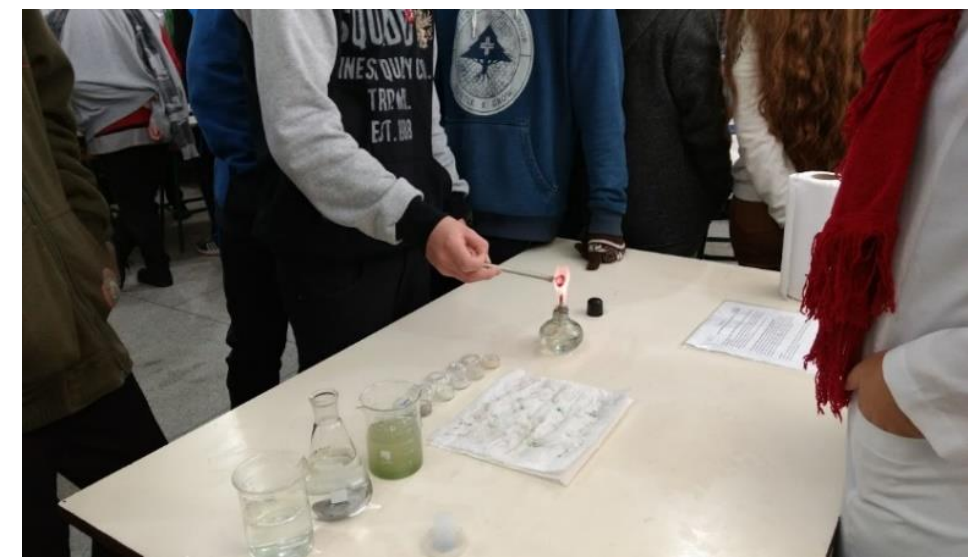

Figura 4- Experimentos apresentados no Colégio Estadual Santa Rosa. (a) Soluções aquosas: ácidos e bases, escala de pH e condutividade elétrica; (b) Teste de chama. Fonte: arquivos do projeto "Química na Prática” (PROEC 114/2016).

Após a apresentação dos experimentos, no sistema de rodízio descrito no item materiais e métodos, foram aplicados questionários de avaliação para os estudantes, cujo preenchimento é facultativo. Dos 136 alunos atendidos na Escola Estadual Prof. Máximo Atílio Asinelli, 83 \% responderam ao questionário (Figura 5a), dos 261 estudantes atendidos no Colégio Estadual Prof. Lysímaco Ferreira da Costa, 90 \% responderam os questionários (Figura 5b) e dos 212 estudantes atendidos no Colégio Estadual Santa Rosa, 82 \% responderam o questionário (Figura 5c). De um total de 609 estudantes atendidos, obtivemos $89 \%$ de questionários preenchidos. A análise desses questionários revelou que o índice de satisfação com o projeto (resposta da pergunta 1 do questionário) variou de 95 a 97\%, que 91-95\% participariam novamente do projeto e que de 97 a 100\% gostaram do projeto. Esses índices indicam que o projeto foi bemsucedido em despertar o interesse pela Química. Entretanto, a resposta às perguntas 3,4 e 5 do questionário revelou que apenas 76 a $86 \%$ dos alunos entenderam e aprenderam com os fenômenos ocorridos nos experimentos. Esse índice, aparentemente baixo quando comparado aos itens anteriores, pode ser considerado alto em se tratando de uma disciplina que não é de fácil compreensão pela maioria da população. Apenas a resposta às perguntas 3 e 4 obteve mais respostas "talvez" (12 a 24\%) do que os demais itens questionados. Acredita-se que este fato decorra do curto espaço de tempo em que o estudante participa de cada experimento (em média 10 minutos) e à falta de entendimento ou conhecimento do assunto na aula teórica, uma vez que o assunto pode não ter sido abordado em sala de aula ainda.

Os estudantes do ensino médio ficaram bastante entusiasmados em participar dos experimentos, em muitos dos experimentos ofertados, eles próprios podiam executá-los com Revista Extensão em Foco, nº 17, Out./ Dez. (2018), p. 149 -163. 
segurança, como pode ser observado nas figuras 3a (verificando a condutividade de soluções aquosas) e $4 \mathrm{~b}$ (fazendo o teste de chama de um sal), ainda, verificar a acidez ou basicidade de produtos do cotidiano (Figura 4a), fazer o "teste do bafômetro" nas reações de oxirredução (Figura 2b), misturar reagentes e observar se há evidência de reação, sintetizar o polímero poliuretana (Figura 3b) e separar misturas (Figura 2a). Essas atividades interativas do projeto contribuíram na divulgação da Química para os estudantes do ensino médio e na troca de saberes, atingindo o nosso objetivo de despertar o interesse pela disciplina de Química. Benedetti Filho e Benedetti (2011) descreveram a importância da atividade de experimentação em Química para promover a divulgação científica e verificaram a sua influência nas escolhas por cursos de graduação: $22 \%$ dos alunos participantes de seu projeto optaram em realizar curso de graduação na área de Química, o qual anteriormente ao projeto não houve nenhuma escolha. Dominguini et. al. (2014) também notaram, em seu projeto de extensão, que os experimentos serviram para aproximar a Química de seus potenciais futuros alunos e permitir o acesso a atividades experimentais. Farias et. al. (2009) discutiram a importância das atividades experimentais no ensino de Química, mostrando que a realização de experimentos ajuda a aproximar a Química vista na sala de aula do cotidiano dos alunos, tornando assim as aulas mais dinâmicas. Essas atividades colaboram para que o aluno consiga observar a relevância do conteúdo estudado e possa atribuir sentido a este, o que incentiva a uma aprendizagem significativa e, portanto, duradoura. Medeiros et. al. (2013) relataram que os alunos gostam muito de aulas práticas, principalmente quando envolvem assuntos atuais como foi a proposta do projeto, com a destilação do petróleo.

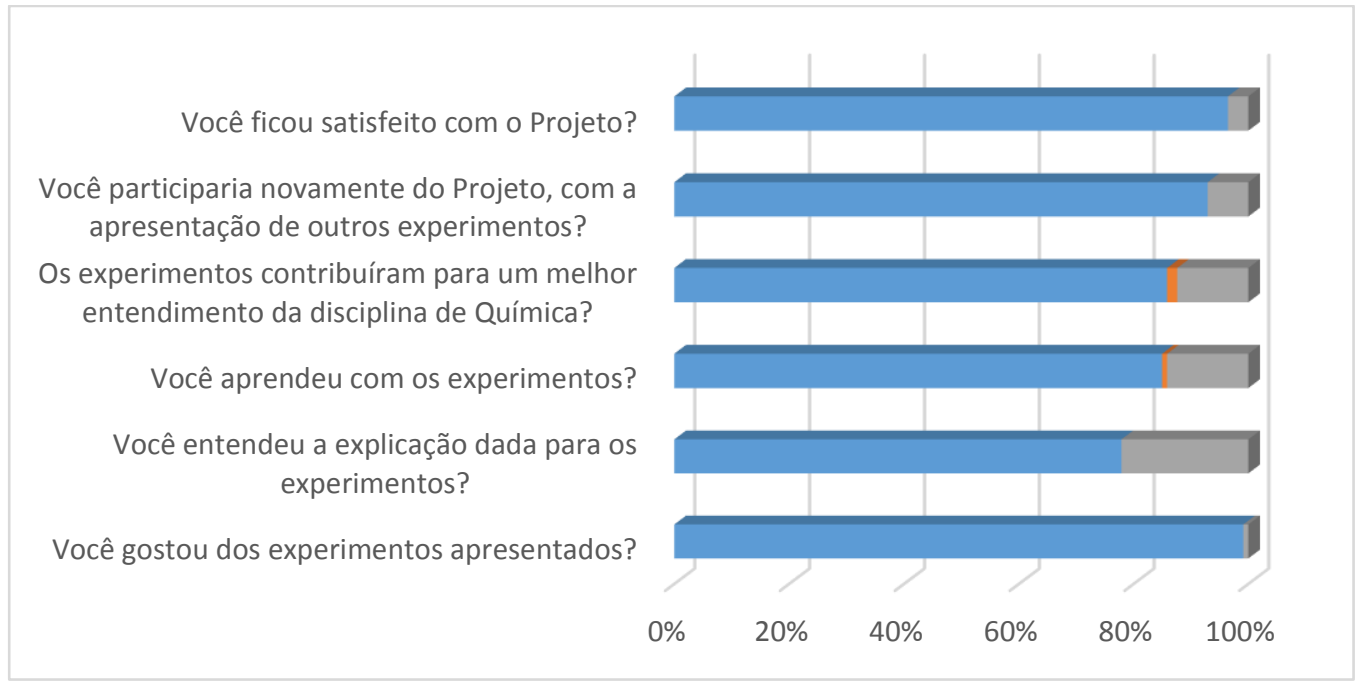

Revista Extensão em Foco, nº 17, Out./ Dez. (2018), p. 149 -163. 
(b)

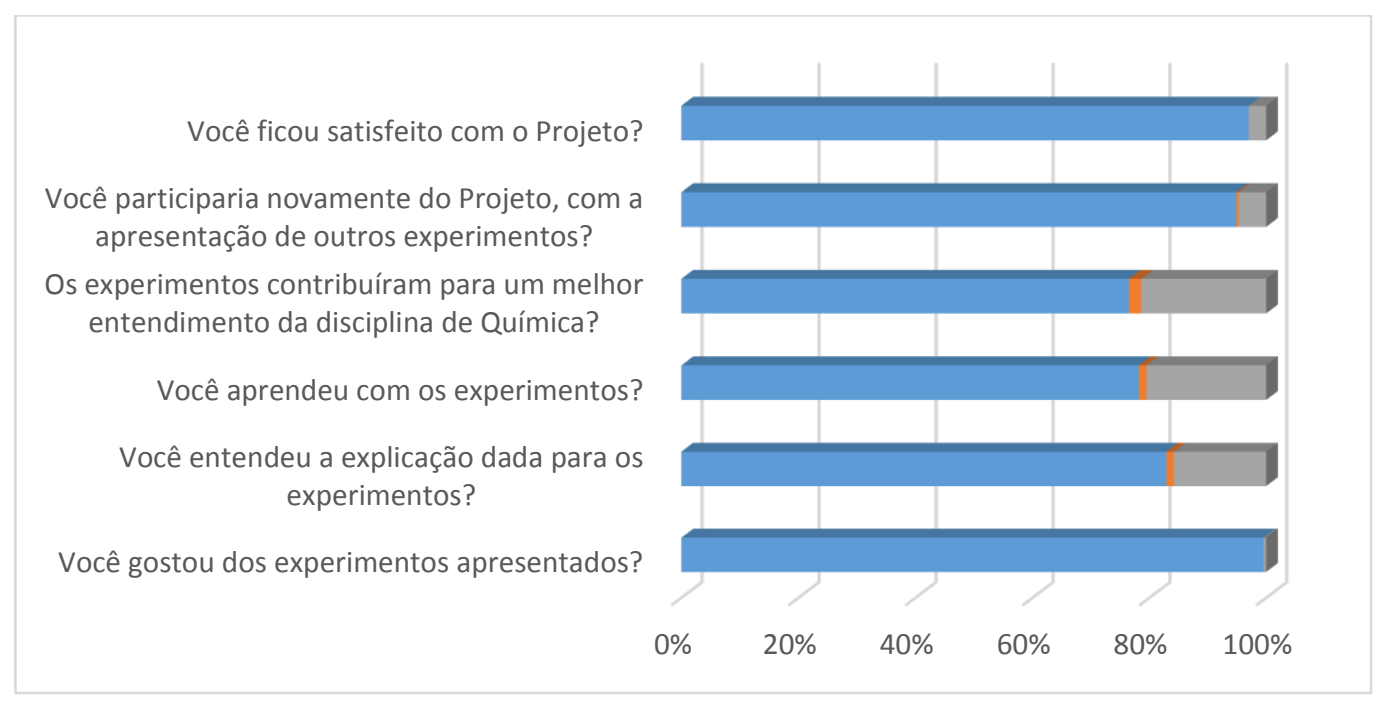

(c)

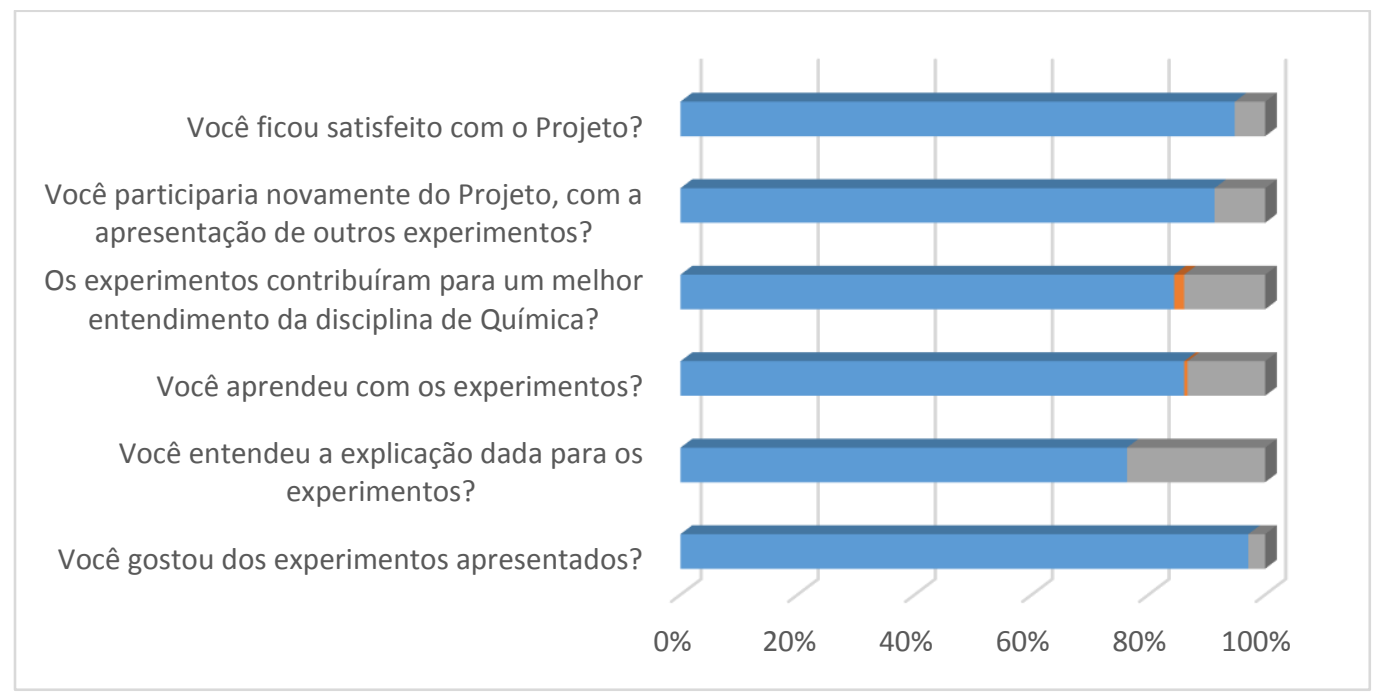

Figura 5- Questionário facultativo aplicado aos estudantes do ensino médio das escolas: Colégio Estadual Prof. Máximo Atílio Asinelli (b) Colégio Estadual Prof. Lysímaco Ferreira da Costa (c) Colégio Estadual Santa Rosa. Legenda: sim não talvez Fonte: Dados dos pesquisadores (2017).

O interesse por atividades experimentais de Química também pode ser notado, nos dias atuais, pela disponibilidade para venda de kits de experimentos de Química para crianças a partir de 12 anos. Também, são vendidos vários livros como o livro "Show de Química: aprendendo Química de forma lúdica e experimental”. Este livro enfatiza o aprendizado de Química, trazendo várias experiências de forma a despertar o encantamento desta ciência pelos alunos e assim facilitar o aprendizado dos conceitos teóricos. $\mathrm{O}$ autor sugere utilizar as experiências como atividade escolar complementar (JESUS, 2013). Portanto, a realização desse

Revista Extensão em Foco, nº 17, Out./ Dez. (2018), p. 149 -163. 
projeto de extensão contempla a necessidade atual de experimentos de Química serem utilizados para auxiliar na compreensão dos conteúdos teóricos da disciplina de Química.

O projeto também teve uma avaliação bastante positiva pelas professoras das escolas, que também preencheram um questionário específico para o professor. Neste questionário as perguntas foram: (1) O projeto complementa os assuntos teóricos abordados em sala? (2) Contribui para a aprendizagem dos estudantes? (3) Os experimentos foram explicados adequadamente pelos alunos de graduação, com desenvoltura e conhecimento? (4) Você ficou satisfeito com o projeto? (5) Sua turma participaria novamente do projeto? (6) Você indicaria o projeto para um colega? Uma das professoras afirmou que a parceria com a UFPR é excelente porque as escolas estaduais sofrem com a escassez de reagentes. Foi notado que, além da falta de reagentes e materiais, os professores das escolas públicas não são incentivados e não têm condições de utilizarem o espaço de laboratório que, normalmente, são utilizados como depósitos. Assim, as professoras pretendem manter a parceria com o projeto agendando mais visitas, uma vez que os estudantes ficaram entusiasmados com as atividades, como relatou uma professora, expressando como os alunos ficaram encantados com os experimentos e mudaram seu pensamento em relação à Química.

Os professores de Química e de Ciências, de modo geral, mostram-se pouco satisfeitos com as condições de infraestrutura de suas escolas, principalmente, aqueles que atuam em instituições públicas, sendo justificado, com frequência, a não realização das atividades experimentais devido à falta destas condições de infraestruturas (GONÇALVES; MARQUES, 2006). Além da falta destas condições, muitos trabalhos também citam as dificuldades para a implementação das aulas experimentais à falta de tempo e dificuldade por parte dos professores para o preparo as aulas laboratoriais. (CUNHA, 1995) e (MEDEIROS, 2013).

Em relação aos estudantes voluntários de graduação, eles executaram e prepararam os experimentos antes de apresentá-los, além de estudarem sobre o tema abordado em seu experimento específico. Nesse momento, eles passaram por um processo de aprendizado sobre o tema e buscaram as melhores maneiras de transmiti-los aos estudantes do ensino médio. Os experimentos tiveram explicação teórica simples, induzindo os estudantes a relacionarem teoria e prática envolvidas em cada experimento. Assim, durante a apresentação, os voluntários explicaram e instigaram a curiosidade dos estudantes das escolas sobre o tema de cada kit de experimento. Os voluntários ficaram bastante satisfeitos em contribuírem com esse processo de transferência de conhecimento.

Revista Extensão em Foco, nº 17, Out./ Dez. (2018), p. 149 -163. 
Os 12 experimentos montados pelo projeto, até o momento, estão disponíveis ao público na forma de apostila, cujo download pode ser feito no site: www.quimica.ufpr.br/paginas/quimica-na-pratica/ na aba Experimentos. A apostila contém a explicação do tema de cada experimento, materiais e métodos, descrição de como executar o experimento, questionamento com resposta sobre os experimentos e curiosidades. Os experimentos abrangem quase todo o conteúdo abordado na disciplina de Química do ensino médio.

Uma das metas desse Projeto, no atual momento, é sua expansão, através do aumento da sua divulgação nas escolas públicas, incentivo de mais professores do ensino público a participarem, aumento do número de estudantes voluntários de graduação e agendamento de novas visitas às escolas públicas de ensino médio de Curitiba e região metropolitana além de visitas dessas escolas ao Departamento de Química-UFPR.

\section{Conclusões}

Os estudantes do ensino médio atendidos pelo Projeto de Extensão "Química na Prática" tiveram oportunidade de participar de atividades experimentais em suas próprias escolas públicas. Essas atividades interativas contribuíram para divulgação da Química entre os estudantes do ensino médio despertando um maior interesse por essa disciplina. Os estudantes voluntários de graduação contribuíram para a transferência de conhecimento e se sentiram fortalecidos em termos teóricos, metodológicos e de cidadania. Ademais, o projeto incentivou professores a utilizarem mais os laboratórios como ferramenta de ensino.

\section{Agradecimentos}

Agradecemos ao Departamento de Química da UFPR, aos estudantes voluntários de graduação dos cursos de Química, Engenharia Química e Farmácia da UFPR e às professoras de Química das Escolas Estaduais que participaram do Projeto.

\section{Referências Bibliográficas}

AMARAL, L. Trabalhos práticos de Química. São Paulo-SP: Livraria Nobel, 1996.

Revista Extensão em Foco, nº 17, Out./ Dez. (2018), p. 149 -163. 
ARROIO, K.M. et.al. O show da Química: motivando o interesse científico. Química Nova. São Paulo -SP, v. 29, $\mathrm{n}^{\mathrm{o}} 1$, p. 173-178, 2006. Disponível em: http://quimicanova.sbq.org.br/detalhe_artigo.asp?id=2447. Acesso em: 06 mar 2018.

BENEDETTI FILHO, E.; BENEDETTI, L.P.S. Experimentação em Química com processo motivador da ciência. Cidadania em Ação: Revista de Extensão e Cultura. Joinville-SC, v.5 n 1 (2011). Disponível em: http://www.revistas.udesc.br/index.php/cidadaniaemacao/article/view/2230. Acesso em: 05 $\operatorname{mar} 2018$.

CHASSOT, A. I. Catalisando transformações na educação. Ijuí-RS: Ed. Unijuí, 1993.

CUNHA, M. O bom professor e sua prática. 5. ed. Campinas-SP: Papirus, 1995.

DOMINGUINI, L. et.al. Projeto de extensão como ferramenta na difusão de conhecimentos químicos. UDESC em Ação. Joinville-SC, v.8, $\mathrm{n}^{\circ} 2,2014$. Disponível em: http://www.revistas.udesc.br/index.php/cidadaniaemacao/article/view/4416. Acesso em: 08 mar 2018.

FARIAS, C.S. et.al. A importância das atividades experimentais no Ensino de Química. $1^{\circ}$ ENCONTRO PARANAENSE DE EDUCAÇÃO EM QUÍMICA-UEL, Londrina-PR, 2009. Disponível em: http://www.uel.br/eventos/cpequi/Completospagina/18274953820090622.pdf. Acesso em: 06 mar 2018.

GASPAR, A.; MONTEIRO, I.C.C. Atividades experimentais de demonstrações em sala de aula: uma análise segundo o referencial da teoria de Vygotsky. Investigações em Ensino de Ciências. Porto Alegre-RS, v. 10, $\mathrm{n}^{\mathrm{o}}$ 2, p. 227-254, 2005. Disponível em: https://www.if.ufrgs.br/cref/ojs/index.php/ienci/article/view/518/315. Acesso em: 04 abr 2018.

GIORDAN, M. O papel da experimentação no ensino de ciências. Química Nova na Escola. São Paulo -SP, $\mathrm{n}^{\mathrm{o}}$ 10, p. 43-49, 1999. Disponível em: http://qnesc.sbq.org.br/online/qnesc10/pesquisa.pdf. Acesso em: 05 mar 2018.

GONÇALVES, F.P.; MARQUES, C.A. Contribuições pedagógicas e epistemológicas em textos de experimentação no ensino de Química. Investigações em Ensino de Ciências, Porto Alegre-RS, v. $11, \quad \mathrm{n}^{\circ} \quad 2, \quad$ p. 1- 22, $2006 . \quad$ Disponível em: https://www.if.ufrgs.br/cref/ojs/index.php/ienci/article/view/494/297. Acesso em: 04 abr 2018

JESUS, H.C. Show de Química: aprendendo Química de forma lúdica e experimental. 2a edição. Vitória-ES: Gráfica e Editora GSA, 2013.

MEDEIROS, A.S. et.al. Importância das aulas práticas no ensino de Química. IX CONGRESSO DE INICIAÇÃO CIENTÍFICA DO IFRN. Natal-RN, 2013. Disponível em: http://portal.ifrn.edu.br/pesquisa/editora/livros-para-download/anais-do-ix-congic-ifrn. Acesso em: 07 mar 2018.

Revista Extensão em Foco, nº 17, Out./ Dez. (2018), p. 149 -163. 
POLETTI, N. Estrutura e Funcionamento do Ensino Fundamental. 26a ed. São Paulo-SP: Ática, 2001.

RESOLUÇÃO No72/11-CEPE.Disponível em: http://www.soc.ufpr.br/portal/?s=72\%2F11 Acesso em: 07 mar 2018.

VYGOTSKY, L. S. A formação social da mente. São Paulo-SP: Editora Martins Fontes, 1989.

ZANON, L.B. e MALDANER, O.A. A Inovação na Área de Educação Química. Química Nova na Escola. São Paulo-SP, $\mathrm{n}^{\mathrm{o}}$ 35, p. 48-56, 2013. Disponível em: http://qnesc.sbq.org.br/online/qnesc35_1/08-PE-91-11.pdf. Acesso em: 05 mar 2018.

Revista Extensão em Foco, nº 17, Out./ Dez. (2018), p. 149 -163. 